\title{
Generosidade versus Interesse Próprio: Juízos Morais de Crianças e Adolescentes
}

\author{
Liana Gama do Vale ${ }^{1}$ \\ Universidade de São Paulo \\ Heloisa Moulin de Alencar \\ Universidade Federal do Espírito Santo
}

\begin{abstract}
RESUMO - Este estudo investigou, em contexto psicogenético, que lugar a generosidade ocupa no universo moral de crianças e adolescentes em contraposição à satisfação de um interesse próprio. Foram entrevistados, individualmente, 30 alunos de uma escola pública de Vitória-ES, os quais foram divididos em três grupos de acordo com a faixa etária (7, 10 e 13 anos). Foi utilizada uma história-dilema que trazia um conflito entre a possibilidade de manifestar a generosidade e a oportunidade de satisfazer um interesse próprio. Em todas as faixas etárias pesquisadas, a maioria dos participantes optou pela generosidade em detrimento da satisfação do próprio interesse. A porcentagem dessa resposta na faixa etária de 10 anos, contudo, foi inferior às porcentagens nas demais idades estudadas. Pode-se afirmar, portanto, que a generosidade faz parte do universo moral infantil e adolescente. Este trabalho contribui para a expansão do campo de pesquisas sobre a moralidade e oferece importantes subsídios para propostas de educação moral que contemplem virtudes como a generosidade.
\end{abstract}

Palavras-chave: juízo moral; generosidade; interesse próprio.

\section{Generosity versus Self Interest: Moral Judgment of Children and Adolescents}

\begin{abstract}
This study investigated, on a psychogenetic context, the place occupied by generosity in children's and adolescents' moral universe as opposed to the satisfaction of self-interest. Thirty students from a public school at VitóriaES, divided in three groups, according to their age (7,10 and 13 years old), were individually interviewed. It was used a story-dilemma which aroused a conflict between the possibility of manifesting generosity and the opportunity of satisfying self-interest. It was verified that, in all age groups, the majority of the participants chose generosity instead of satisfaction of their own self-interest. The percentage of this answer in the 10-year-old age group, however, was inferior to the percentage in the other age groups. It can be affirmed that generosity is a part of the moral universe of children and adolescents. This study contributes to the expansion of research on morality and offers important subsidies to moral education proposals that enhance virtues such as generosity.
\end{abstract}

Keywords: moral judgment; generosity; self-interest.

$\mathrm{O}$ tema dos direitos e deveres ainda permanece central no panorama das produções científicas que se dedicam à moralidade. Estudos sobre virtudes, com exceção da justiça, são raros na literatura da área. Mas, afinal, o que é uma virtude? E qual a sua relação com a moral?

Para respondermos a essas questões, comecemos por fazer uma distinção entre moral e ética. La Taille (2002a), embora ressalte que as duas palavras são, na base, sinônimas, propõe uma possível diferença entre os dois termos, que nos será útil neste estudo:

“(...) chamamos de moral um conjunto de deveres, logo de obrigações ou imperativos que o sujeito coloca para si. A moral corresponde à pergunta: como devo agir? Chamemos de ética as buscas e preocupações acerca da felicidade, da realização de uma vida plena. A ética corresponde às perguntas: Que vida

1 Endereço: Programa de Pós-Graduação em Psicologia - Universidade Federal do Espírito Santo (UFES). Avenida Fernando Ferrari, ${ }^{\circ}$ 514, Goiabeiras. Vitória, ES. CEP 29075-910. E-mail: lianadovale@yahoo.com.br. viver? ou Que vida vale a pena viver? Naturalmente, assim definida, a ética não remete a deveres, mas sim a aspirações" (pp. 157-158).

É importante acrescentar que, embora tenham significados distintos, moral e ética são complementares e indissociáveis. De acordo com La Taille (2001b), ao respondermos que vida viver?, remetemos-nos à pergunta como devo agir? $\mathrm{O}$ autor ressalta, ainda, que a primeira pergunta implica uma outra: quem eu quero ser? Ora, tal pergunta coloca em pauta o tema da construção do Eu. Definamos, então, esse objeto singular do conhecimento.

La Taille (2001b), com base nas proposições do autor francês Roger Perron (1991), define o Eu como um conjunto de representações de si: “(...) são imagens, idéias, conceitos que cada pessoa tem de si” (p. 74). É importante notar que o termo é empregado no plural, já que, de acordo com o autor, cada indivíduo não faz apenas uma representação de si mesmo, mas várias, que podem, inclusive, ser contraditórias entre si. La Taille (2002b) ressalta, ainda, que as representações de si são construídas como conjunto de 
valores, que podem ser positivos ou negativos. Mas o que é valor do ponto de vista psicológico?

É investimento de afetividade, conforme afirma Piaget (1954). Assim, quanto maior a carga afetiva vinculada a determinado valor, mais central é o seu posicionamento no conjunto das representações de si do indivíduo. Já aqueles valores que possuem força motivacional menor ocupam a periferia desse conjunto (La Taille, 2001b). Dessa forma, uma pessoa que costuma roubar objetos alheios, porque não quer trabalhar para ganhar seu próprio dinheiro, certamente confere maior força motivacional a valores contraditórios com regras morais como não roubar. Em decorrência, tais valores ocupam uma posição central no sistema de representações de si dessa pessoa.

La Taille (2001b) destaca três tipos de valores associados às representações de si: valores não morais, como a beleza física, a fama ou a glória; valores imorais, como, por exemplo, ser violento; e valores coerentes com as regras morais, como a justiça. Há, ainda, segundo o autor, valores que, além de serem coerentes com as regras morais, conferem sentido às referidas regras, garantem a sua aplicação e ampliam sua significação humana. "Estes valores éticos são as virtudes" (La Taille, 2001b, p. 82), que também podem compor as representações de si do ser humano.

Em um primeiro momento, Comte-Sponville (1995/1997) define virtude como função de determinado objeto, como poder, mas poder específico. Assim, a virtude da faca é cortar, que não pode ser a mesma que a da enxada, por exemplo. Já no homem, continuando com o mesmo autor, virtude é uma maneira de ser e agir humanamente, é o esforço para agir bem, visto que o bem não é para ser contemplado, mas para ser feito. Assim, podemos dizer que virtude é a disposição do caráter para fazer o bem.

Se a ética se refere à busca da felicidade, faz sentido incluirmos nela as virtudes. Se, para respondermos à questão da ética, nos remetemos à questão da moral, podemos afirmar que as virtudes não só são coerentes com as leis morais, como “(...) correspondem a traços de caráter, sem os quais as leis podem permanecer letra morta" (La Taille, 2001b, p. 85).

Apresentado o tema das virtudes e a sua possível inserção no campo da moral, discutamos, então, sobre a virtude que elegemos estudar nesta investigação: a generosidade.

Comecemos apontando algumas diferenças entre essa virtude e a justiça, considerada o carro-chefe da moralidade. Segundo Comte-Sponville (1995/1997):

(...) a generosidade é mais subjetiva, mais singular, mais afetiva, mais espontânea, ao passo que a justiça, mesmo quando aplicada, guarda em si algo mais objetivo, mais universal, mais intelectual ou mais refletido. A generosidade parece dever mais ao temperamento; a justiça, ao espírito ou à razão (p. 97).

Comte-Sponville (1995/1997) define generosidade como a virtude do dom. Godbout (1992/1992) qualifica dom como "toda prestação de bens ou de serviços efetuada, sem garantia de retribuição (...)" (p. 30). Quando se é generoso, nada se reivindica, por isso, Comte-Sponville afirma que essa virtude não pode ser objeto de uma lei. Esse desprendimento presente no ato generoso não ocorre na justiça, que tem a reciprocidade como uma de suas características: “(...) faz sentido alguém ao mesmo tempo sentir-se no dever de ser justo e no direito de exigir que o tratem justamente" (La Taille, 2000, p. 116). Na justiça, o auto-interesse, ao lado do interesse pelo outro, está sempre presente: "A lei justa é boa para todos, inclusive para a pessoa que exerce a justiça" (La Taille, 2006b, p. 62). Na generosidade, todavia, apenas o interesse pelo outro está em jogo. Nas palavras de La Taille (2006b): "O ato de generosidade favorece quem é por ele contemplado, não quem age de forma generosa. É por ser a generosidade a inteira dedicação a outrem que digo que ela traduz plenamente o altruísmo" (p. 62).

Apresentadas algumas diferenças entre a generosidade e a justiça, comparemos, agora, a generosidade com a solidariedade. Embora essas duas palavras sejam, muitas vezes, utilizadas como sinônimas, julgamos necessário apontar as diferenças. Basta consultarmos o dicionário (Houaiss \& Villar, 2001) para notar que, enquanto a generosidade se refere à liberalidade, bondade e magnanimidade, a solidariedade diz respeito à interdependência, cooperação, responsabilidade mútua, mutualidade de interesses e deveres ou vínculo recíproco. Nesse caso, ajudamos o outro porque, dessa forma, nos ajudamos. Comte-Sponville (1995/1997) ressalta que esse valor parte do princípio do agir para receber ou mesmo para se livrar de uma ação constituída na sociedade como um dever, no sentido de preocupar-se com o bem coletivo e com as agruras que os grandes desastres naturais impõem a determinados indivíduos (como enchentes e terremotos). Em relação à generosidade, o autor acrescenta: “... a solidariedade pode motivá-la, suscitá-la, reforçá-la, não há dúvida. Mas ela só é verdadeiramente generosa desde que vá além do interesse, ainda que bem compreendido, ainda que partilhado - logo, contanto que vá além da solidariedade!" (Comte-Sponville, 1995/1997, p. 101).

É útil saber, ainda, que a generosidade, não raras vezes, exige sacrifício, esforço contra tendências adversas e reflexão, por isso essa virtude aponta para a excelência (La Taille, 2001a). Analisemos o conteúdo de uma história-dilema utilizada por Eisenberg (1983) para melhor compreendermos essa questão: uma criança que se dirigia a uma festa depara no caminho com alguém que caíra e se machucara. Ora, parece-nos lícito afirmar que há aí um conflito interno a ser resolvido por essa criança: ser generosa para com o outro e deixar de ir à festa ou ir à festa e não ser generosa para com o outro.

Sabemos que a generosidade, diferentemente da justiça, não pode ser objeto legítimo de reivindicação pessoal. Na situação apresentada, por exemplo, a pessoa que caiu não poderia exigir ser tratada de forma generosa. La Taille (2000) ressalta, contudo, que algumas pessoas generosas podem ser movidas por um sentimento de dever quando colocam para si a obrigação de agir com generosidade. Tal dever, no entanto, não procede do direito do outro, mas do valor moral dessa virtude. Vale frisar que o sentimento pessoal de dever pode incidir tanto sobre condutas que correspondem a uma exigibilidade social (por exemplo, não mentir), quanto sobre condutas não exigíveis pela sociedade, como a generosidade (La Taille, 2006a). Mas, afinal, como podemos definir o "dever"?

La Taille (2006b) define o dever como um tipo particular de querer. Segundo o autor, "querer" e "dever" não devem ser pensados como opostos, mas como "quereres" diferentes: 
(...) somente age moralmente quem se sente intimamente obrigado a tal, e não quem é coagido por algum poder exterior. Logo, o sujeito moral é, por definição, livre, porque é ele mesmo quem decide agir por dever. Dito de outra forma, somente é moral quem assim o quer (La Taille, 2006b, p. 54).

Voltemos ao conteúdo da história-dilema em questão. Se considerarmos que a criança em conflito, depois de refletir, decide deixar de fazer um programa desejável (ir à festa) para ser generosa com a pessoa que caíra, parece-nos válido afirmar que ela mesma se obriga a cumprir o seu dever. Dessa forma, não podemos atribuir a razão de seu gesto a outra coisa senão ao seu querer. Mas ela também não queria ir à festa? Sim. Trata-se, nesse caso, de "quereres" conflitantes, e, se a criança opta por deixar de ir à festa para ajudar a pessoa machucada é porque o querer manifestar a generosidade é mais forte para essa criança do que o querer satisfazer seu próprio interesse. La Taille (2006b) relaciona o "querer" ao "ser", que, conforme vimos anteriormente, consiste em um conjunto de representações de si. Ora, na situação apresentada, a generosidade parece ser um valor central nas representações de si da referida criança, já que o querer "ajudar o outro" foi mais forte para ela do que o querer "ir à festa".

Tognetta (2006), ao realizar um estudo com adolescentes de 12 a 15 anos de idade sobre a generosidade ligada às representações de si, encontrou correspondência entre os juízos morais relacionados a essa virtude e as representações que os participantes têm de si mesmos. Segundo a autora, os adolescentes cujas representações de si são caracterizadas por conteúdos éticos apresentam juízos mais evoluídos no que diz respeito à generosidade e à sensibilidade aos sentimentos dos personagens envolvidos nas situações apresentadas.

Mas por que, entre tantas virtudes, elegemos a generosidade? Um importante argumento, utilizado por La Taille (2000) em favor de um estudo psicológico de virtudes como a generosidade, é a possibilidade desta desempenhar um papel na gênese da moralidade. La Taille e cols. (1998), a partir da realização de pesquisas sobre as virtudes morais segundo as crianças, constataram que a generosidade faz parte do universo moral infantil. Os autores verificaram que a maioria das crianças de 6 anos já afirma que um personagem que se priva de uma fruta predileta para dá-la ao irmão (generosidade) é moralmente mais admirável do que outro que segue uma regra justa como dividir um pacote de biscoitos destinado a ele e ao irmão. Os resultados dessa pesquisa destacam a relevância psicológica da generosidade na construção da moral, já que, de acordo com a perspectiva construtivista, as estruturas superiores se alimentam das formas e dos conteúdos das estruturas inferiores. "Vale dizer que podemos levantar a hipótese de que, no caminho para a construção do ideal de justiça, a generosidade (...) desempenha um papel" (La Taille, 2000, p. 118).

A essa primeira hipótese, La Taille (2006a) acrescenta uma outra: "a generosidade não somente é virtude presente no início da gênese da moralidade, como é mais bem assimilada e, portanto, integrada à consciência moral, do que a justiça nessa mesma fase do desenvolvimento". É importante ressaltar, todavia, que, de acordo com Piaget (1932/1994), no início da gênese da moralidade, a criança se limita a obedecer às regras impostas pela autoridade por medo de ser castigada ou de perder o seu amor. Como a criança pequena poderia, então, melhor assimilar a generosidade, se essa virtude, diferentemente da justiça, é tão pouco dependente das imposições do adulto?

La Taille (2006b) afirma que o universo moral infantil vai além das relações de coação e da obediência cega a figuras de autoridade. Ao lado do amor e do medo, o autor menciona outros sentimentos que devem comparecer na dimensão afetiva dessa fase do desenvolvimento moral, a saber: confiança, simpatia, indignação e culpa. Dos sentimentos citados, destaquemos a simpatia, que, de acordo com La Taille, tem íntima relação com a generosidade.

A simpatia, segundo Piaget (1954), é um sentimento baseado em juízos de valor mútuos entre os indivíduos e ocorre mediante um contato perceptual. Para o filósofo Adam Smith (1759/1999), a simpatia nos faz experimentar as situações de outras pessoas e dividir com estas os sentimentos que tais circunstâncias tendem a despertar. Tal acepção aproxima-se de uma das definições de simpatia apresentadas no dicionário: faculdade de compenetrar-se das idéias ou sentimentos de outrem (Houaiss \& Villar, 2001). Para La Taille (2006a), a simpatia se refere a um 'operador emocional', passível de motivar uma pessoa a preocupar-se com outra. No que diz respeito às nuanças que separam algumas definições do termo, é importante ressaltar que, neste trabalho, simpatia será entendida como a capacidade humana de comover-se com os estados afetivos alheios.

Definido o sentimento de simpatia no contexto deste estudo, estabeleçamos a sua relação com a virtude generosidade. Nas palavras de La Taille (2006a):

No que tange à relação entre generosidade e simpatia (...), ela é clara, uma vez que o exercício da referida virtude pressupõe perceber-se a necessidade singular de uma determinada pessoa (ou grupo de pessoas), e contemplá-la por intermédio de um 'dom de si'. Uma pessoa por ventura incapaz de simpatia talvez nem percebesse a necessidade alheia, certamente não se comoveria com ela, e, por conseguinte, não agiria de forma generosa (p. 12).

Se a generosidade é inspirada pela simpatia, o exercício dessa virtude é produto da sensibilidade da criança mais do que de sua disposição para obedecer à autoridade adulta (La Taille, 2006b). É justamente esse aspecto que leva La Taille (2006a) a apresentar a hipótese de que a generosidade é mais bem assimilada do que a justiça por parte das crianças pequenas. Sabemos que, na fase da heteronomia, as regras de justiça são impostas pelo adulto e, conforme Piaget (1932/1994), permanecem exteriores à consciência da criança. Os atos de generosidade inspirados pela simpatia, todavia, são espontâneos e, de acordo com La Taille (2006b), favorecem uma compreensão mais autônoma do valor dessa virtude. Segundo o autor, “(...) enquanto a regra imposta dá mais ênfase à obediência do que à pessoa-alvo da ação proibida, a simpatia faz o contrário, dando mais visibilidade a outrem e, por conseguinte, a uma das razões essenciais de ser da moral" (La Taille, 2006b, p. 118).

Para testar a referida hipótese, La Taille (2006a) realizou uma pesquisa com crianças de 6 a 9 anos de idade. $O$ autor solicitou aos participantes que atribuíssem sentimentos a per- 
sonagens injustos e não generosos. Os resultados mostraram que as crianças de 6 anos, em sua grande maioria, atribuem sentimentos positivos ao personagem que comete uma injustiça, já que ele conquistou o que queria com tal ato. As mesmas crianças, no entanto, atribuem sentimentos negativos ao personagem que falta com a generosidade, concebendo o desconforto experimentado por ele. O resultado encontrado nos leva a considerar, portanto, que a generosidade ocupa, sim, um lugar diferenciado no universo moral das crianças menores.

Se a generosidade já faz parte do pensamento das crianças pequenas, torna-se urgente abrir espaço para a sua expressão e favorecer a sua legitimação. Mas o que se tem feito atualmente para que as crianças cultivem virtudes como a generosidade?

Tognetta (2003) investigou a ação de ambientes escolares na construção da solidariedade, também entendida como generosidade pela autora. Ao apresentar dilemas que envolviam esse valor a crianças de duas escolas diferentes, Tognetta verificou que as respostas dos alunos advindos de um ambiente cujas relações se baseavam na cooperação foram mais propensas à solidariedade do que as respostas dos alunos de um ambiente cujas relações eram baseadas na coerção.

Embora pesquisas como essas demonstrem a importância das relações de cooperação, muitas escolas preferem manter um ambiente coercitivo diante das encruzilhadas do trabalho diário com seus alunos. No entanto, mesmo com a imposição severa de regras e limites restritivos, a agressividade, o desrespeito, a violência e a indisciplina têm sido recorrentes na prática dos protagonistas escolares. La Taille (2001b) acredita que os atos indisciplinados dos alunos, uma das principais reclamações dos professores atualmente, estão mais relacionados à falta de projetos de vida do que à ausência de firmeza e ordem. E virtudes como a generosidade ampliam os valores que inspiram as respostas dos estudantes para as perguntas sobre tais projetos; portanto, enriquecem o campo da educação moral (La Taille, 2001b).

Se considerarmos que a generosidade enriquece o campo da educação moral, parece-nos pertinente, então, contribuir para a elaboração de propostas pedagógicas que possam favorecê-la. Mas como podemos tornar esse valor sensível ao pensamento dos alunos? É o último ponto que devemos analisar.

Segundo Piaget (1931/1998), os educadores devem entender que o ensino precisa ser oferecido de acordo com a evolução dos interesses do aluno, visto que uma prática educativa só terá alcance se responder a uma necessidade e corresponder a realidades experimentadas e espontaneamente vividas pela própria criança. De acordo com o autor: "Devese conduzir a criança do individual para o universal. E o único meio de fazê-lo é (...) utilizar a psicologia da criança" (Piaget, 1931/1998, pp. 76 e 77).

Antes de dedicarmo-nos à elaboração de uma proposta de educação moral que favoreça a construção do valor da generosidade, faz-se necessário, portanto, debruçar-nos sobre a singularidade dessa virtude e investigar o seu lugar no universo moral infantil e adolescente. Assim, este estudo teve como objetivo pesquisar, em um contexto psicogenético, o lugar que ocupa o valor da generosidade em contraposição à satisfação de um interesse próprio, ou seja, averiguar o que alunos de 7 a 13 anos julgam ser mais importante: a generosidade ou a satisfação do próprio interesse.

\section{Método}

\section{Participantes}

Participaram deste estudo 30 alunos de uma escola pública do município de Vitória - ES: 10 alunos de 7 anos, 10 de 10 anos e 10 de 13 anos de idade, igualmente divididos quanto ao sexo.

\section{Procedimento}

Realizamos entrevistas individuais de acordo com o método clínico proposto por Piaget (1926/n.d.; 1932/1994). Utilizamos como instrumento uma história-dilema que exigia uma tomada de decisão, por parte dos participantes, acerca do que deveria fazer um personagem diante de um conflito entre a possibilidade de manifestar a generosidade para com um vizinho e a oportunidade de satisfazer um interesse próprio. Vale ressaltar que os personagens da história foram descritos com a mesma idade e o mesmo sexo do aluno entrevistado no momento. Eis a história e as perguntas apresentadas aos participantes:

Fernando tem 7 anos de idade e gosta muito de nadar. Depois de uma semana inteira de chuva, o sol, finalmente, apareceu. Como era domingo, seus pais o convidaram para ir à praia. Ele achava que aquele dia era perfeito para nadar e estava muito feliz por isso. Quando Fernando estava saindo de casa, seu vizinho, João, da sua idade, o chamou para brincar. Ele estava com a perna engessada e, por isso, não podia ir à praia. João não tinha ninguém para brincar com ele naquele dia e parecia muito triste. (Versão feminina: Fernanda e Maria)
a) O que você acha que Fernando deveria fazer?
b) Por quê?

Todas as entrevistas foram gravadas na íntegra e transcritas. Priorizamos a análise qualitativa dos dados e utilizamos, em termos percentuais, uma referência quantitativa, que nos auxiliou na apresentação e discussão dos resultados. Assim, elaboramos categorias para as respostas e justificativas dos participantes e, em seguida, inserimos os dados em uma planilha do programa estatístico SPSS for Windows (1999). Como nosso objetivo está relacionado a um interesse psicogenético, cruzamos as categorias elaboradas com as idades dos participantes da pesquisa.

\section{Resultados e Discussão}

A maior parte dos participantes $(80 \%)$ optou pela generosidade em detrimento da satisfação de um interesse próprio. É importante destacar, todavia, que $26,7 \%$ dos participantes que optaram pela generosidade tentaram, inicialmente, conciliar a ação generosa com a satisfação do próprio interesse:

\footnotetext{
Se fosse eu, eu chamaria a Fernanda para ir para a praia porque eu estava com muita vontade mesmo de ir à praia, aí, a gente brincaria ou faria alguma coisa na areia da praia, sem precisar ir à água. Aí, eu perguntaria a ela se eu poderia ir à água dar uma mergulhadinha porque eu estava com muita vontade e voltaria para brincar com ela ou pediria ao meu pai
} 


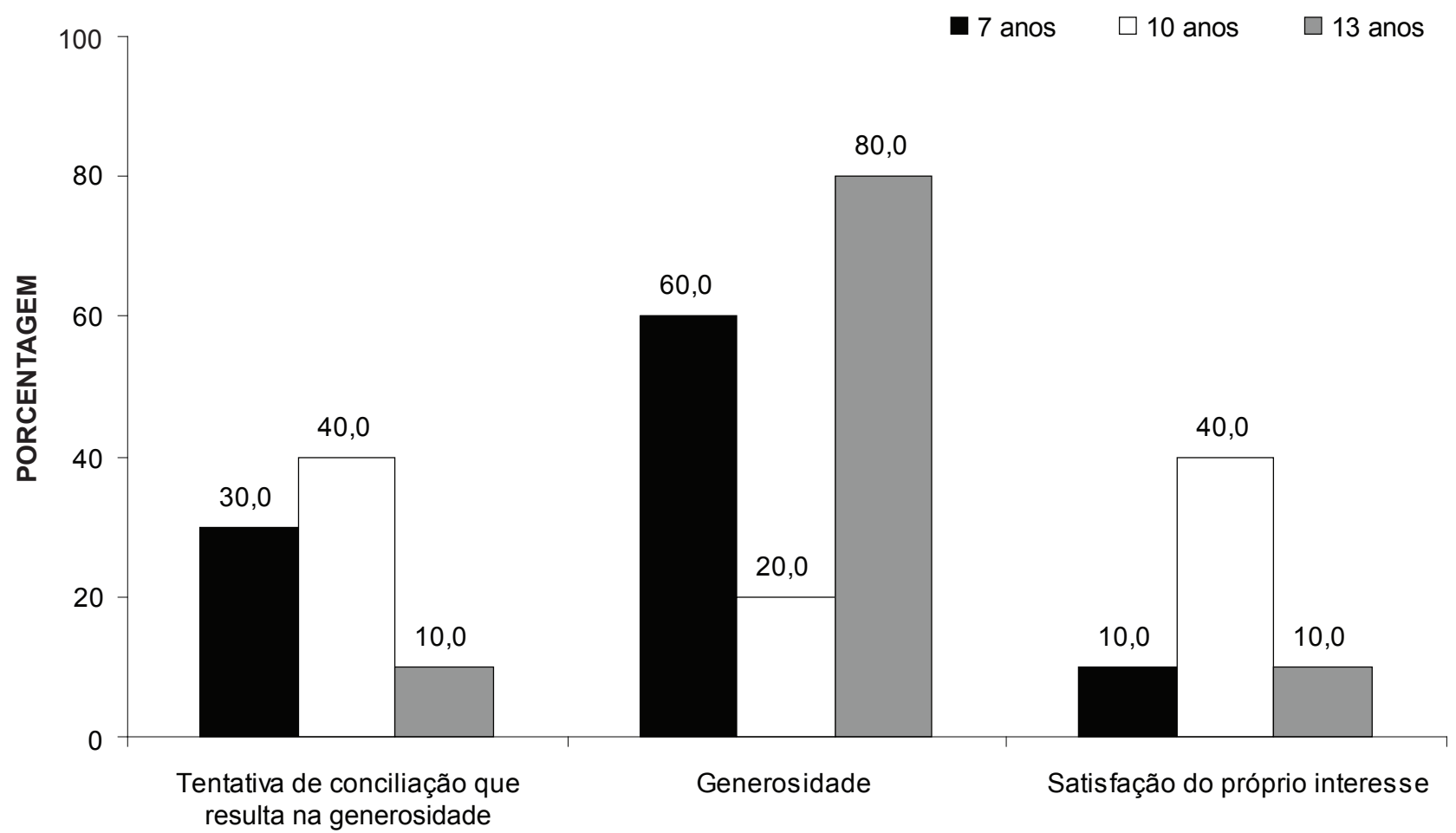

TIPOS DE RESPOSTAS

Figura 1. Generosidade em contraposição à satisfação do próprio interesse: comparação das respostas dos participantes conforme a idade.

para, pelo menos, levá-la um pouquinho no mar, sem molhar o gesso (Karina, 13; 10) .

Tais participantes ofereceram uma alternativa interessante para a resolução do dilema, já que, apesar de tomarem a perspectiva do outro, procuraram equilibrar os próprios desejos de forma que a ação generosa ficasse bem para o vizinho e para si mesmo. La Taille (2002a) afirma que o sentimento de auto-interesse, ilustrado nas respostas de alguns de nossos participantes, não é contraditório com a moral, já que esta não implica sistematicamente abdicar dos próprios interesses. As crianças e adolescentes que apresentaram esse tipo de resposta prestaram atenção às necessidades do outro e mobilizaram-se para supri-las, mas demonstraram uma preocupação com o bem-estar próprio. Há uma tentativa de generosidade aí?

Conforme vimos anteriormente, na generosidade apenas o interesse pelo outro está presente. Ora, ao tentarem conciliar a generosidade com a satisfação de um interesse próprio, nossos participantes não demonstraram essa inteira dedicação ao outro, pressuposta pela virtude generosidade. Vale dizer, no entanto, que os mesmos participantes aproximaram-se dessa virtude quando apresentamos uma contra-argumen-

2 Todas as vezes que citarmos a resposta ou a justificativa de um participante, apresentaremos, em seguida, um nome próprio e dois números separados por ponto-e-vírgula, ambos entre parênteses. O primeiro dado diz respeito ao nome fictício do entrevistado para não comprometermos o seu anonimato. Já os números representam a idade do participante em anos e meses. Assim, "13; 10" indica 13 anos e 10 meses de idade. tação a essa alternativa e mostramos a impossibilidade da conciliação que propunham. Diante de tal impossibilidade, julgaram que o personagem deveria brincar com seu vizinho (generosidade) e deixar de ir à praia com os pais (satisfação de um interesse próprio).

Comparemos, agora, esse dado com os resultados da pesquisa de Tognetta (2003), que, ao investigar a influência de ambientes escolares na construção da solidariedade na criança, fez uso de histórias-dilema contrapondo esse valor com a satisfação de um interesse próprio. Conforme relatamos anteriormente, embora a autora use o termo "solidariedade", a história que utilizou traz uma situação em que a virtude generosidade poderia ser manifestada para com o outro. Conheçamos, então, os resultados encontrados por Tognetta ao entrevistar alunos de 6 a 7 anos de idade. Segundo a autora, $26,47 \%$ dos participantes provenientes de um ambiente cujas relações se baseiam na cooperação tentaram conciliar a solidariedade com a satisfação do próprio interesse, enquanto $11,43 \%$ dos alunos advindos de um ambiente coercitivo apresentaram o mesmo tipo de resposta. Tais dados mostram que algumas crianças mais novas são capazes de tentar conciliar os dois elementos conflitantes, inclusive aquelas inseridas em contextos onde as relações assimétricas predominam.

A Figura 1 apresenta a porcentagem de cada tipo de resposta apresentada pelos participantes. Como pode ser observado, embora tenhamos encontrado essa tentativa de conciliação em todas as idades pesquisadas, esse tipo de 
resposta predominou na faixa etária de 10 anos. A maior parte dos entrevistados de 13 anos $(80 \%)$ e de 7 anos (60\%) apresentou uma disposição direta para essa virtude.

Se juntarmos a porcentagem dos participantes que apresentaram uma tentativa de conciliação que resultou na generosidade com a porcentagem dos participantes que decidiram de forma direta por essa virtude, obteremos a seguinte distribuição: 90\% dos participantes de 7 anos, 60\% de 10 anos e 90\% de 13 anos. De acordo com essa distribuição e com os dados apresentados na Figura 1, fica claro que não encontramos gênese nas respostas deste estudo. Embora a opção pela generosidade predomine em todas as faixas etárias, chama-nos a atenção a variação de porcentagem referente às respostas dos entrevistados de 10 anos. Mas discutamos tais resultados iniciando pela menor faixa etária de nosso estudo.

A alta porcentagem dos participantes de 7 anos que optaram pela generosidade comprova a presença dessa virtude no início do desenvolvimento moral da criança, já verificada em outros estudos sobre o tema. Como vimos anteriormente, $\mathrm{La}$ Taille e cols. (1998) verificaram que, aos 6 anos de idade, as crianças já são capazes de diferenciar ações inspiradas pela generosidade e ações inspiradas pela obediência a uma regra justa, sendo que as primeiras ações são mais admiradas por elas do que as segundas.

Sabemos que a precocidade da generosidade tem íntima relação com o sentimento de simpatia, dimensão afetiva moralmente relevante e presente no início da gênese da moralidade na criança. La Taille (2006b) afirma que a generosidade é mais inspirada pela simpatia do que pela disposição a obedecer a figuras de autoridade, já que a educação moral dada pelos pais costuma incidir mais sobre regras proibitivas do que sobre incentivos de ações generosas. Mas, se a presença da generosidade no início da gênese da moralidade pode ser explicada pelo sentimento de simpatia, já encontrado em crianças de 7 anos, como podemos explicar a queda da porcentagem de respostas de generosidade na faixa etária de 10 anos?

Conforme já discorremos, Tognetta (2003) verificou que os ambientes escolares influenciam na construção da solidariedade, já que alunos de uma escola onde predominava a cooperação apresentaram respostas mais propensas à solidariedade do que estudantes provenientes de outra escola onde as relações de coerção prevaleciam. Esse dado é bastante interessante, mas será que pode fundamentar uma hipótese para os dados que encontramos? Todos os nossos entrevistados estudavam na mesma escola e no mesmo horário, mas em salas de aula diferentes, de acordo com a idade que tinham. Assim, os participantes de 7 anos cursavam a $1^{\mathrm{a}}$ série; os de 10 anos, a $4^{\mathrm{a}}$ série e os de 13 anos, a $7^{\mathrm{a}}$ série do ensino fundamental. Não era nosso objetivo investigar o tipo de relação predominante nos diversos ambientes dessa escola, mas acreditamos que as relações existentes em cada sala de aula não poderiam diferir tanto dos demais espaços da instituição, a ponto de influenciarem os juízos sobre a generosidade nos alunos de 10 anos. Portanto, acreditamos que essa primeira hipótese é pouco provável.

Voltemos, então, ao sentimento de simpatia. O que nos intriga até o momento é que, se esse sentimento é experimentado pela criança menor, podemos afirmar o mesmo em relação às crianças de 10 anos, o que dificulta a compreensão dos dados sobre a generosidade que encontramos para essa idade. Vale ressaltar, no entanto, que, como a simpatia se refere a um juízo de valor, ela irá transformar-se no decorrer do desenvolvimento e da vida (La Taille, 2006b). Dessa forma, o que comoveu a grande maioria dos participantes de 7 anos na história contada pode não ter comovido uma boa parte dos entrevistados de 10 anos. Mas, diante dessa afirmação, e considerando que a porcentagem de respostas que apontam para a generosidade é a mesma nas faixas etárias de 7 e 13 anos, poderíamos supor que os estados afetivos alheios que afetam as crianças de 7 anos são os mesmos que comovem os adolescentes de 13 anos? Ora, nada podemos afirmar nesse sentido, já que nosso instrumento e procedimento não foram elaborados para investigar a gênese do sentimento de simpatia nas três faixas etárias em questão. Consideremos, então, um outro aspecto referente à precocidade da generosidade.

Embora a simpatia seja uma forte motivação para atos de generosidade, “(...) ela não é nem garantia perene de ações morais, nem sentimento necessário a todas as expressões da moralidade" (La Taille, 2006b, p.116). Não podemos afirmar, assim, que o sentimento de simpatia é suficiente para a decisão pela generosidade, o que não implica desprezar o seu papel na gênese da moralidade. Vale lembrar, então, que, no início do desenvolvimento moral, outros sentimentos comparecem além da simpatia. Destaquemos aqui o medo e o amor, ressaltados por Piaget (1932/1994) ao estudar o juízo moral na criança. Vimos que, de acordo com esse autor, as crianças mais novas respeitam as regras impostas pelos adultos por medo de serem punidas ou de perderem o amor das pessoas que representam a autoridade. Todavia, vimos também que, segundo La Taille (2006b), a generosidade está pouco relacionada às imposições das figuras de autoridade. Mas não poderíamos supor que, ao lado do sentimento de simpatia, o medo de perder o amor da autoridade também inspira a opção pela generosidade da criança pequena? Não poderíamos supor que a criança de 7 anos pode tomar a sua decisão de acordo com o que imagina que a autoridade gostaria que ela fizesse? Ora, se aceitarmos essa suposição, poderemos pensar em uma nova hipótese para nossos dados.

Sabemos que é justamente por volta dos 10 anos de idade que as crianças costumam distanciar-se da referência a figuras de autoridade. Tal fato não poderia explicar a porcentagem mais baixa de respostas de generosidade dos participantes de 10 anos quando comparada à porcentagem dos entrevistados de 7 anos? Acreditamos que sim. Mas, nesse caso, como explicaríamos a alta porcentagem dessas respostas na faixa etária de 13 anos? Ora, é possível que nossos participantes mais velhos tenham optado pela generosidade pelo fato de essa virtude ser um valor central nas suas representações de si, e não por julgarem ser a opção mais desejada pela autoridade. Avaliemos alguns dados de pesquisa que contribuem para essa discussão.

Tognetta (2006), ao realizar um estudo sobre a generosidade ligada às representações de si, solicitou que adolescentes de 12 a 15 anos avaliassem uma história que tinha como foco a falta de generosidade de um personagem para com outro. Segundo a autora, a maior parte dos participantes considerou que o personagem que não manifestou a generosidade não agiu bem. Apenas 10,67\% das respostas pareceram apontar para o descaso para com o personagem que carecia de ajuda. 
Esses dados, de certa forma, reforçam a hipótese que acabamos de apresentar, já que a faixa etária pesquisada pela autora abarca a idade de nossos participantes mais velhos.

Vejamos, agora, como os participantes justificaram as respostas apresentadas. Conforme mostra a Tabela 1, as justificativas mencionadas foram distribuídas em cinco categorias. Vale destacar que a grande maioria dos participantes apresentou mais de uma justificativa para suas respostas, por isso o número total de justificativas é superior à quantidade de entrevistados.

Como podemos perceber na Tabela 1, a maioria das justificativas apresentadas (70\%) encontra-se na categoria condições de quem precisava de ajuda. Vale dizer que as condições mencionadas pelos entrevistados, na maioria das vezes, faziam parte do conteúdo da própria história: “(...) o João não tinha ninguém para brincar, estava triste e não podia ir à praia porque estava com a perna engessada" (Fábio, 13; 5). Alguns participantes, no entanto, a partir das condições que relatávamos, acrescentavam alguns detalhes ao justificarem suas respostas: "Porque o vizinho dele estava doente, estava com a perna quebrada e estava impossibilitado de sair, brincar lá fora, só podia ficar preso dentro de casa, não podia sair para lugar algum" (Daniel, 13; 9). Ao falarem dessas condições, nossos participantes não demonstram uma capacidade de comoção com o estado em que o outro se encontrava? Não há aí um tipo de sensibilidade para com o sofrimento do outro? Ou melhor: não podemos destacar o sentimento de simpatia nessas justificativas? Parece-nos lícito responder que sim. Dessa forma, considerando que a grande maioria dos participantes que optou pela generosidade apresentou essa justificativa, nossos resultados demonstram que esse sentimento parece ser forte motivação para juízos que apontam para o exercício dessa virtude.

Conforme podemos verificar na Tabela 1, não encontramos gênese nessa categoria. Há uma predominância desse tipo de justificativa nas faixas etárias de 7 e 13 anos. Encontramos, todavia, uma prevalência da faixa de idade de 10 anos na categoria seguinte da referida tabela: condições de quem precisava tomar a decisão. Tal fato pode ser explicado pela distribuição das respostas dos participantes. Essa segunda categoria de justificativa se refere às respostas que apontam para a satisfação de um interesse próprio. Ora, como vimos anteriormente, a porcentagem correspondente a tais respostas é maior na faixa de idade intermediária de nosso estudo.

Notamos, então, que as condições também são ressaltadas pelos participantes que optam pela satisfação do próprio interesse, mas, aqui, tais participantes referem-se às condições do outro personagem da história contada: aquele que precisava decidir entre os dois elementos em conflito. Essas condições, na maioria das vezes, também estavam presentes no conteúdo do dilema: "Porque ela ficou uma semana sem nadar e ela estava morrendo de vontade de nadar. Então, na primeira oportunidade que ela teve, ela deveria ir" (Joana, 10; 4).

Tognetta (2003) encontrou respostas semelhantes ao contrapor os dois elementos em questão no estudo que realizou sobre a influência do ambiente escolar na construção da solidariedade. Tais respostas, incluídas pela autora na categoria o bem a si próprio está acima da solidariedade, foram apresentadas por $37,14 \%$ de alunos de um ambiente coercitivo e $2,94 \%$ de estudantes de uma escola onde predominavam as relações de cooperação. De acordo com Tognetta, esses participantes explicitaram a necessidade de satisfazer seus próprios interesses e a adoção de perspectiva do outro não foi constatada em suas respostas.

Entre as justificativas incluídas nessa segunda categoria, destacamos a de Alice $(13 ; 10)$ :

Porque eu acho que, se ela estava com vontade de ir à praia, não seria legal para ela fazer uma coisa contra a vontade dela, entendeu? Não que ela não quisesse fazer companhia para a amiga dela, mas ela iria ficar lá com má vontade. Ela iria ficar lá, mas sem querer, iria ficar meio que por obrigação.

Para Alice, o fato de a personagem fazer algo por obrigação, ou seja, por dever, pressupõe que ela também o faça sem querer. A justificativa dessa participante nos remete à definição de dever como um tipo particular de querer (La Taille, 2006b), discutida anteriormente. Nas palavras de La Taille (2006b): "Não se trata de querer versus dever, mas sim de 'quereres' diferentes (...)" (p. 54). Assim, se a personagem deixasse de fazer um programa prazeroso porque ela mesma se sentia obrigada a ajudar sua vizinha, é porque o querer manifestar a generosidade seria mais forte para ela do que o querer satisfazer seu próprio interesse. Portanto ela poderia ficar com a vizinha

Tabela 1. Generosidade em contraposição à satisfação do próprio interesse: distribuição das justificativas dos participantes conforme a idade.

\begin{tabular}{|c|c|c|c|c|c|c|c|c|}
\hline \multirow{2}{*}{ Justificativa } & \multicolumn{2}{|c|}{7 anos } & \multicolumn{2}{|c|}{10 anos } & \multicolumn{2}{|c|}{13 anos } & \multicolumn{2}{|c|}{ Geral } \\
\hline & $\mathbf{N}^{\mathbf{o}}$ & $\%$ & $\mathbf{N}^{\mathbf{o}}$ & $\%$ & $\mathbf{N}^{\mathbf{o}}$ & $\%$ & $\mathbf{N}^{\mathbf{o}}$ & $\%$ \\
\hline Condições de quem precisava de ajuda & 9 & 90,0 & 4 & 40,0 & 8 & 80,0 & 21 & 70,0 \\
\hline Condições de quem precisava tomar a decisão & 1 & 10,0 & 4 & 40,0 & 1 & 10,0 & 6 & 20,0 \\
\hline Reciprocidade & 2 & 20,0 & 2 & 20,0 & 1 & 10,0 & 5 & 16,7 \\
\hline Possibilidade de adiar a satisfação do próprio interesse & 3 & 30,0 & 3 & 30,0 & 5 & 50,0 & 11 & 36,7 \\
\hline Outros & 2 & 20,0 & 3 & 30,0 & 1 & 10,0 & 6 & 20,0 \\
\hline
\end{tabular}


por dever, mas não sem querer. La Taille afirma que o "querer" depende do "ser", definido pelo autor como um conjunto de representações de si. Dessa forma, se a generosidade fosse um valor central nas representações de si dessa participante, $o$ querer "ficar com a vizinha" (ação generosa) certamente seria mais forte do que o querer "ir à praia" (satisfação do próprio interesse). O que essa participante e os demais entrevistados que apresentaram justificativas da segunda categoria parecem afirmar, no entanto, é justamente o contrário.

Voltemos à Tabela 1 para falar das demais categorias de justificativas apresentadas pelos participantes. A reciprocidade, característica da autonomia moral, foi mencionada por $16,7 \%$ dos entrevistados para justificar a decisão pela ação generosa:

(...) em um outro dia, quando a Fernanda estiver doente, a menina que chamou a Fernanda para brincar poderá ir lá para a casa dela para elas poderem brincar. A Fernanda não poderia pegar praia por estar gripada, e ela não iria gostar que a coleguinha fosse à praia (Ana, 7; 5).

A generosidade expressa por esses participantes parece aproximar-se da idéia de solidariedade, já que eles tendem a ajudar o outro para que, em situações análogas, sejam ajudados também. A presença do interesse, característico da solidariedade, é marcante em suas falas. De acordo com Piaget (1948/1998), a reciprocidade deve ser entendida “(...) como a mútua coordenação dos pontos de vista e das ações" (p. 67). Essa definição fica clara na resposta de um participante a uma contra-argumentação que fizemos. Nessa contraargumentação, contamos ao participante que um menino de uma outra escola disse que o personagem deveria ir à praia, e não brincar com seu vizinho como ele havia sugerido. Eis, então, a resposta de Henrique $(10 ; 8)$ :

Eu queria ver se esse menino de outra escola estivesse no lugar do João. Se ele fosse o João, faça de conta, e estivesse sozinho, não tivesse ninguém para brincar, estivesse lá, sozinho e chamasse um colega dele, e o colega dele fosse para a praia. É a mesma história do João. Por exemplo, o menino que falou que não concorda é o João, e o Fernando sou eu, faça de conta. Aí, o meu pai me chamou para ir à praia, mas, aí, aquele menino me chama para brincar com ele, e ele não concorda? E se fosse ele? Ele iria ficar sozinho. É a mesma coisa.

Ao relacionar o desenvolvimento do juízo moral com o desenvolvimento cognitivo, Piaget (1972/1983) ressalta que reciprocidade implica reversibilidade, ${ }^{3}$ característica do pensamento operatório-concreto, que ocorre por volta dos 7-8 anos de idade. Dessa forma, é possível que os participantes da menor faixa de idade de nossa pesquisa ( 7 anos) apresentem competências intelectuais suficientes para mencionarem a reciprocidade como justificativa de suas respostas. Nossos resultados comprovam tal fato: $20 \%$ dos entrevistados de 7 anos mencionam a reciprocidade como uma das razões para a ação generosa. Essa categoria foi encontrada por Tognetta

3 Na teoria piagetiana, reversibilidade é a capacidade de realizar a mesma ação nos dois sentidos do percurso, mas tendo consciência de que se trata da mesma ação (Montangero \& Maurice-Naville, 1994/1998).
(2003), também com uma porcentagem baixa, na pesquisa que citamos anteriormente com crianças de 6 a 7 anos. Como pode ser visto na Tabela 1, a porcentagem mantém-se baixa nas demais faixas etárias de nosso estudo, sem apontar, portanto, para uma gênese dessa categoria.

Uma outra justificativa da opção pela generosidade foi a possibilidade de adiar a satisfação do próprio interesse, apresentada por $36,7 \%$ dos participantes (ver Tabela 1): "Porque a praia não vai deixar de existir. (...) porque, no outro dia, poderia fazer sol, e ele poderia ir de novo" (Tadeu, 10; 6). Vale ressaltar que dois participantes mencionaram a possibilidade de adiar a satisfação do próprio interesse, ressaltando a impossibilidade de fazer o mesmo com a ação generosa: “(...) porque, na praia, ele pode ir a vários dias da vida dele, agora, brincar com o menino que estava lá triste, com a perna engessada, é só nesse tempo aí, a não ser que ele quebre a perna de novo" (Márcio, 13; 3).

Na última categoria da Tabela 1 (outros), por fim, incluímos as justificativas que não puderam ser introduzidas nas categorias citadas anteriormente, nem apareceram com uma freqüência suficiente para abrirmos uma nova categoria. É útil saber que a maior parte dessas justificativas foram adicionais, ou seja, correspondiam a uma segunda ou até mesmo terceira razão apresentada pelos participantes para suas respostas. Destaquemos algumas delas.

Dois participantes (ambos com 7 anos de idade) fizeram referência ao tipo de vínculo existente entre os personagens da história (eles eram vizinhos). Enquanto um deles utiliza o vínculo para justificar a ação generosa, o outro aponta o mesmo vínculo como uma das razões da decisão pela satisfação do próprio interesse. Vale mencionar, também, que uma participante de 10 anos mencionou a amizade como possível conseqüência da ação generosa para explicar a sua opção pela virtude generosidade.

\section{Considerações Finais}

De posse dos resultados encontrados em nosso estudo, podemos afirmar que a generosidade faz parte do universo moral infantil e adolescente. A alta porcentagem de participantes de 7 anos que optam por essa virtude em detrimento da satisfação do próprio interesse demonstra que a ação generosa é valorizada pela criança pequena.

Este trabalho apresenta apenas uma abordagem inicial ao estudo das virtudes e, em especial, da generosidade. Estudos subseqüentes podem ser sugeridos, utilizando a mesma história-dilema e as categorias que elaboramos, com participantes de idades consecutivas. Assim, poderíamos verificar em quais idades ocorrem as mudanças nos tipos de respostas relativos à referida virtude. Uma pesquisa com tal delineamento, possivelmente, esclareceria se a hipótese que levantamos sobre a porcentagem inferior de respostas de generosidade na faixa etária de 10 anos faz sentido. Nossos dados podem ser utilizados como linha de base.

Por fim, vale acrescentar que este trabalho pode contribuir para a expansão do campo de pesquisas que se dedicam à moralidade e trazer importantes subsídios para propostas de educação moral que considerem o processo de desenvolvimento da criança e do adolescente e contemplem virtudes como a generosidade. 


\section{Referências}

Comte-Sponville, A. (1997). Pequeno tratado das grandes virtudes (E. Brandão, Trad.). São Paulo: Martins Fontes. (Trabalho original publicado em 1995)

Eisenberg, N. (1983). Children's differentiations among potential recipients of aid. Child Development, 54, 594-602.

Godbout, J. T. (1992). O espírito da dádiva (J. P. Cabrera, Trad.). Lisboa: Instituto Piaget. (Trabalho original publicado em 1992)

Houaiss, A. \& Villar, M. S. (2001). Dicionário Houaiss da lingua portuguesa. Rio de Janeiro: Objetiva.

La Taille, Y. (2000). Para um estudo psicológico das virtudes morais. Educação e Pesquisa, 26, 109-121.

La Taille, Y. (2001a). Desenvolvimento moral: a polidez segundo as crianças. Cadernos de Pesquisa, 114, 89-119.

La Taille, Y. (2001b). A questão da indisciplina: ética, virtudes e educação. Em P. Demo, Y. La Taille \& J. Hoffmann (Orgs.), Grandes pensadores em educação: o desafio da aprendizagem, da formação moral e da avaliação (pp. 67-98). Porto Alegre: Mediação.

La Taille, Y. (2002a). Cognição, afeto e moralidade. Em M. K. Oliveira, D. T. R. Souza \& T. C. Rego (Orgs.), Psicologia, educação e as temáticas da vida contemporânea (pp. 135-158). São Paulo: Moderna.

La Taille, Y. (2002b). Vergonha, a ferida moral. Petrópolis: Vozes.

La Taille, Y. (2006a). A importância da generosidade no início da gênese da moralidade na criança. Psicologia: Reflexão $e$ Crítica, 19, 9-17.

La Taille, Y. (2006b). Moral e ética: dimensões intelectuais e afetivas. Porto Alegre: Artmed.

La Taille, Y., Micelli, A., Domingues, C., Kravosac, D. B., Jamra, F. A., Fiorini, F. P., Bronstein, M. \& Neto, S. O. (1998). As virtudes morais segundo as crianças. Relatório Científico FAPESP não-publicado, Instituto de Psicologia da Universidade de São Paulo, São Paulo.

Montangero, J. \& Maurice-Naville, D. (1998). Piaget ou a inteligência em evolução (F. Becker \& T. B. I. Marques, Trad.). São Paulo: Artmed. (Trabalho original publicado em 1994).

Perron, R. (1991). Les représentations de soi. Toulouse: Privat.
Piaget, J. (n.d.). Introdução: os problemas e os métodos. Em $A$ representação do mundo na criança (pp. 5-28), (R. Fiúza, Trad.). Rio de Janeiro: Record. (Trabalho original publicado em 1926)

Piaget, J. (1954). Les relations entre l'affectivité et l'intelligence dans le développement mental del'enfant. Paris: Centre de Documentation Universitaire de la Sorbonne (Paris V).

Piaget, J. (1983). Problemas de Psicologia Genética. Em Os pensadores (pp. 209-294), (2 ed., C. E. A. Di Piero, Trad.). São Paulo: Abril Cultural. (Trabalho original publicado em 1972)

Piaget, J. (1994). O juízo moral na criança ( $2^{\mathrm{a}}$ ed., E. Lenardon, Trad.). São Paulo: Summus. (Trabalho original publicado em 1932)

Piaget, J. (1998). O espírito de solidariedade e a colaboração internacional. Em S. Parrat-Dayan \& A. Tryphon (Orgs.), Sobre a pedagogia (pp. 59-78). São Paulo: Casa do Psicólogo. (Trabalho original publicado em 1931)

Piaget, J. (1998). Para onde vai a educação? (14 ed., I. Braga, Trad.). São Paulo: José Olympio. (Trabalho original publicado em 1948)

Smith, A. (1999). Teoria dos sentimentos morais. (L. Luft, Trad.). São Paulo: Martins Fontes. (Trabalho original publicado em 1759)

Tognetta, L. R. P. (2003). A construção da solidariedade e a educação do sentimento na escola. Campinas: Mercado das Letras, São Paulo: Fapesp.

Tognetta, L. R. P. (2006). Sentimentos e virtudes: um estudo sobre a generosidade ligada às representações de si. Tese de Doutorado não-publicada, Instituto de Psicologia, Universidade de São Paulo, São Paulo.

SPSS for Windows - Statistical Package for Social Sciences (1999). Base 10.0. Application Guide. Chicago, IL.

Recebido em 06.07.2007

Primeira decisão editorial em 21.07.2008

Aceito em 01.02.2008 